\title{
It's Not as Simple as It Seems: Continuous Positive Airway Pressure and Cheyne-Stokes Respiration
}

\author{
Neil S. Cherniack \\ Department of Medicine, UMDNJ - New Jersey Medical School, Newark, N.J., USA
}

In this issue of Respiration, Yasuma [1] reports on 5 cases of congestive heart failure and Cheyne-Stokes respiration (CSR) treated with low levels of continuous positive airway pressure (CPAP) for at least 1 year. The CPAP ameliorated the CSR and improved left ventricular ejection fractions. This confirms previous observations and establishes that quite low levels of CPAP are efficacious [2]. All this seems straightforward. CPAP improves cardiac function by reducing left ventricular overload and the improvement in heart performance leads to a decrease in CSR. But how does it do it? What is the connection between cardiac function and Cheyne-Stokes breathing?

About 50 years ago Guyton et al. [3] artificially increased the circulation time in anesthetized dogs to several minutes and produced in some of them a waxing and waning of ventilation that resembled Cheyne-Stokes breathing observed in humans with heart failure. Engineers had predicted that delays in information transfer in control systems could produce instability by which they meant that the output of the system rather than being constant as a result of control system action instead became oscillatory [4]. Guyton et al. reasoned that the long circulation time delayed information about the level of oxygen and carbon dioxide in the alveolar air from reaching the chemoreceptors in the brain and the carotid body leading to unstable respiratory control. But was that explanation correct?

\begin{tabular}{ll}
\hline KARGER & ( ) 2005 S. Karger AG, Basel \\
0025-7931/05/0722-0132\$22.00/0 \\
$\begin{array}{l}\text { Fax +4161306 12 34 } \\
\begin{array}{l}\text { E-Mail karger@karger.ch } \\
\text { www.karger.com }\end{array}\end{array}$ & $\begin{array}{l}\text { Accessible online at: } \\
\text { www.karger.com/res }\end{array}$
\end{tabular}

Guyton et al. required exceptionally long circulation times to produce CSR, far greater than that observed in patients with heart failure who exhibited that kind of breathing. The dogs were anesthetized and might have experienced brain damage as a result of the complex experimental procedures used. CSR commonly occurs with brain damage brought on by cerebrovascular accidents and it has been proposed that decreased brain function is necessary for CSR to appear [5]. Supporting this view were studies that showed oscillating patterns in the electroencephalogram, in papillary diameter, and in cerebral blood flow coincident with the oscillations in breathing [6]. From the very first the patient seemed to wake up in the phase in which breathing increased, and lapse back to coma as breathing decreased [7].

More recent investigations of the respiratory control system and the study of central apneas seem to have brought some reconciliation between the apparently antagonist ideas that CSR was caused either by brain or by heart disease. The findings can be summarized as follows. CSR is instability of the respiratory control system. Respiration is affected by stimuli occurring in multiple systems of the body, and the respiratory rhythm in turn pervades the behavior of neurons that regulate many different systems. Information delays (long circulation times) are just one of the factors that that produce instability of respiratory control manifested by CSR. Additional factors that

Dr. Neil S. Cherniack

Office of the Dean, Department of Medicine

UMDNJ - New Jersey Medical School, 185 South Orange Avenue

Newark, NJ 07103-2714 (USA)

Tel. +1 973972 7937, Fax +1 973972 7104, E-Mail cherniac@umdnj.edu 
frequently occur in patients with congestive heart failure include: hypoxia due to interstitial edema which increases controller responses to $\mathrm{CO}_{2}$ (increased controller gains are an important cause of unstable control) and a loss of alertness caused by poor sleep and fatigue and in some by low cerebral blood flow [8]. It is noteworthy that in the Yasuma paper [1] sleep quality as well as cardiac function improved. Perhaps even more important these different factors controller gains, circulation times and alertness interact to produce instability together even when one of these factors alone cannot.

Are there lessons here for the etiology and treatment of obstructive apnea? Are obstructive apneas caused just by a problem in the upper airways? First there is evidence that control system instability may be important in obstructive as well as in central apneas [9, 10]. Airway obstruction results often from a combination of factors both anatomical and functional, which depend on the relative responsiveness of chest wall and upper airway muscles to chemical and neural stimuli. Arousal is sometimes related to airway obstruction but not always, and may have adverse effects of its own [11]. In addition there is increasing evidence that obstructive apneas are often just one element in a syndrome of altered metabolism that affects many systems [12]. CPAP keeps the airways open and it is important in preventing many of the adverse consequences of the metabolic syndrome, but it may not always treat the basic problem.

\section{References}

1 Yasuma F: Cheyne-Stokes respiration in congestive heart failure: Continuous positive airway pressure of $5-8 \mathrm{~cm} \mathrm{H}_{2} \mathrm{O}$ for 1 year in five cases. Respiration 2005;72:198-201.

$\checkmark 2$ Naughton MT, Liu PP, Bernard DC, Goldstein RS, Bradley TD: Treatment of congestive heart failure and Cheyne-Stokes respiration during sleep by continuous positive airway pressure. Am J Crit Care Med 1995;151:92-97.

-3 Guyton AC, Crowell JW, Moore JW: Basic oscillating mechanism of Cheyne-Stokes breathing. Am J Physiol 1956;187:395-398.

$\checkmark 4$ Glass L, Mackey MC: Pathological conditions resulting from instabilities in physiological control systems. Ann NY Acad Sci 1979;316: 214-235.
5 Bassetti C, Aldrich MS, Quint D: Sleep-disordered breathing in patients with acute supraand infratentorial strokes: A prospective study of 39 patients. Stroke 1997;28:1765-1772.

$\checkmark 6$ Trinder J, Merson R, Rosenberg JI, Fitzgerald F, Kleiman J, Bradley TD: Pathophysiological interactions of ventilation, arousals, and blood pressure oscillations during Cheyne-Stokes respiration in patients with heart failure. Am J Crit Care Med 2000;162:808-813.

7 Cheyne $\mathrm{J}$ : A case of apoplexy in which the fleshy part of the heart was converted into fat. Dublin Hosp Rep 1818;2:216-223.

8 Longobardo G, Evangelista CJ, Cherniack NS: Effects of neural drives on breathing in the awake state in humans. Respir Physiol 2002; 129:317-333. $\checkmark 9$ Longobardo GS, Gothe B, Cherniack NS, Fishman AP: Sleep apnea considered as a control system instability. Respir Physiol 1982;50: 311-333.

10 Younes M, Ostrowski M, Thompson W, Leslie C, Shewchuk W: Chemical control stability in patients with obstructive sleep apnea. Am J Crit Care Med 2001;163:1181-1190.

11 Younes M: Role of arousals in pathogenesis of obstructive sleep apnea. Am J Crit Care Med 2004; 169;623-633.

12 Vgontzas AN, Chrousos GP: Sleep, the hypothalamic-pituitary-adrenal axis, and cytokines multiple interactions and disturbances in sleep disorders. Endocrinol Metab Clin North Am 2002;31:15-36. 